\title{
BUILDING NEW SPACES FOR EDUCATION THROUGHOUT LIFE, APRENDO+ COURSES
}

\author{
Jorge Leon-Martinez, Edith Tapia-Rangel, National Autonomous University of Mexico
}

(UNAM), Mexico

\section{Abstract}

In this paper the study case of the Aprendo+ courses is presented as a proposal of the so-called lifelong learning, which the UNAM offers to the Spanishspeaking community, seeking to return the knowledge generated within the university to society. The Aprendo+ courses are self-learning and are supported by the use of ICT.

\section{Introduction}

Times are constantly changing, so people that makeup societies must be prepared to face them appropriately. Lifelong learning is a valuable tool to achieve this preparation. To meet these individual and collective needs of modern communities, universities can actively participate by articulating strategies and particular initiatives or through partnerships to promote lifelong learning. In this way, universities will continue being the leading depositories of the knowledge society. To attain such goal, it is vital the support of Information and Communication Technologies (ICT), which provides resources to promote new ways to teach and learn. Furthermore, open and self-learning courses can be offered as a return on investment in the university to society. Considering all the previous aspects, the Coordination of Open University and Distance Education (CUAED) developed a lifelong learning project called Aprendo+ Courses.

\section{Lifelong Learning Initiative}

The origin of the term lifelong learning came from the '70s when it was called Lifelong Education. It intended to seek a more human development for people and communities to face the vertiginous social changes. Later on, in the ' $90 \mathrm{~s}$, the term was transformed into lifelong learning linked to the training and knowledge of new skills that allowed people to face changing work demands. (Medel-Añonuevo et al, 2001)

As well, lifelong learning seeks to provide knowledge, experience, skills, abilities, and attitudes to achieve personal enrichment, development, social inclusion, democratic 
citizenship, and employment. Lifelong learning includes "learn to know," "learn to be," "learn to do," "learn to live together," "learn to change," and "learn to transform," to achieve all of them, it is necessary to develop the ability to "learn to learn."(Badat, 2013)

Lifelong education should be paramount in developing countries that seek to solve problems such as the gaps between urban and rural societies, low schooling, violence, democratic participation and corruption. Taking this into consideration, in these regions, lifelong education could address the following aspects:

- "Resilience and self-esteem, so that people are capable of responding positively to change;

- Team work and cooperation, so that people can work together on issues;

- Creativity and problem solving, so that people can pioneer new solutions;

- Independence of mind and critical thinking, so that they can analyse issues and persist despite scepticism or opposition from conventional thinking;

- Learning to learn, so that people are able to continue learning effectively throughout life;

- Public speaking, presentation and communication skills, so that people can get engaged with a wider public more effectively;

- Political and citizenship skills, so that people can take part indecision-making effectively;

- Global power structures and processes;

- Core concepts and knowledge of sustainable development and global interdependence;

- Appropriate values and attitudes" (Alexander, 2002).

Thus, to develop education projects throughout life, the following challenges must be considered:

- Lifelong learning should seek the optimization of individual differences in learning, as they are the key to solving our past experiences, to diminish the effect of negative hereditary factors that influence learning;

- Lifelong learning must provide continuous learning experiences to allow people to achieve self-growth, self-realization, skill development, knowledge acquisition, and creativity development;

- Promote a lifelong learning culture, placing it above every individual culture (Medel-Añonuevo et al., 2001).

\section{Support Provided by Self-Learning}

Self-learning is a crucial component of the skills of this century as linked to lifelong learning. It is a demand of modern society, as pointed by various international 
organizations such as UNESCO (United Nations Educational, Scientific and Cultural Organization) and the OECD (Organisation for Economic Co-operation and Development). By self-learning, we mean any increase in knowledge, skills, achievements, or personal development that an individual selects and achieves by their efforts, using any method, in any circumstance or moment. (Chee et al., 2011).

Self-learning should consider the following three aspects:

- Possession of learning shown when the learner can identify, determine and articulate their own learning goals, identify learning activities to achieve the meeting goals, visualize their progress in learning, and challenge themselves by establishing their indicators of achievement of learning goals;

- Management and monitoring of their learning. The learner must ask questions and generate relevant research, explore their range of possibilities and make decisions, self-plan and self-manage their time, be critical of their learning, and be able to seek support from others to achieve their learning goals;

- Extension of their learning. The learner applies what he has learned in new contexts and uses the skills he or she has acquired to learn beyond formal content (Chee et al., 2011).

\section{Lifelong Education from the University Perspective}

Universities must fulfil a prominent role within the dynamics of the so-called knowledge society. In this society, the dominant institutions seek that people meet the requirements of the new knowledge-based industries. Although not all universities have recognized this new world and adapted to it. Thus, universities now face new actors competing with them in the quest to educate people. (Alexander, 2002)

In this regard, the European Association of Universities (Smidt \& Sursock, 2011) organized a working group for lifelong education that agreed to point out that if universities adopt lifelong learning strategies they can generate benefits for their societies in the following aspects:

- Economic aspect: by promoting an increase in productivity, economic growth, wealth creation, improvement of the knowledge base, and increase in employment opportunities and social policy;

- Social aspect: by improving people's health and quality of life, stimulating new approaches to social problems, changing community attitudes, informing public policies and promoting public debate;

- Environmental aspect: by improving the environment and lifestyle, optimizing waste management, reducing pollution, improving the management of natural 
resources, reducing the consumption of fossil fuels and achieving adaptation to climate change;

- Cultural aspect: by improving society's understanding regarding who we are and where we come from as a nation and as a society, preserving and enriching culture, and bringing new ideas and forms of a nation.

Likewise, the aforementioned group discovered a series of aspects in which universities must commit to develop and implement lifelong learning initiatives, which are:

- Incorporate the concepts of extending coverage and lifelong learning into institutional strategies;

- Provide education and learning to a diversified population;

- Adapt the study programs to ensure that they are designed to achieve wider participation and attract more adult learners;

- Provide appropriate guidance and counselling services;

- Recognize previous learning;

- Incorporate lifelong learning into the institution's quality culture;

- Strengthen the relationship between research, teaching and innovation from the perspective of lifelong learning;

- Consolidate reforms that promote a creative and flexible learning environment for all students;

- Develop alliances at local, regional, national and international levels in order to offer attractive and relevant programs;

- Be a reference for institutions that promote lifelong learning (Smidt \& Sursock, 2011).

\section{Social aspect: by improving people's health and quality of life, stimulating new approaches to social Education and ICT}

Information and communication technologies have been the fundamental element for the growth of various educational forms, mainly in the open and online modalities, which have provided new opportunities for lifelong learning in many countries.

Kanwar and others (2011) claim that some of the main tendencies in the use of ICT in education are: the significant expansion of the organizations' potential for spreading their scope of operations and influence beyond their traditional geographical boundaries; and the increase in collaborative exchange and the generation of visible knowledge in the socalled collective intelligence and training of the masses, which break the school boundaries, while the creation of dynamic knowledge and social computing tools and processes are more widespread and accepted. 
Nowadays, ICTs are one of the essential means to support informal learning and selflearning, which are the most important mechanisms for gaining and improving skills and competencies, primarily through electronic networks of interests and professions. These electronic networks of interests and occupations are constituted as important spaces to access and share information, and to collaborate in the development of skills and competencies collectively.

\section{Open Educational Resources}

Open Educational Resources (OER) are teaching, learning, and researching materials in any medium that reside in the public domain and released under a free license that allows access, use, reuse, and redistribution by others, with limited restrictions or without restrictions. (Atkins, Brown, \& Hammond, 2007)

A relevant aspect regarding these resources is its quality to be open. In this sense, three independent areas distinguished where the concept of openness manifested, they are: the social, the technical, and the nature of the resource itself. The term open, in the social area, is based primarily on the expected social benefits and ethical considerations related to the freedom to be used, contributed, and shared. In the technical field, open means that the resource is operable at both the technological and functional level. The nature of the resource itself is that any individual can enjoy it as others can, and the resources are not contrary but public goods.

As well, open educational resources have the enormous potential to improve the quality and effectiveness of education by permitting some situations: greater availability of relevant and high quality learning resources, cost reduction of accessing educational materials; easy adaptation favoured by permissive license use encouraging the development of new ways for students to be more active participants in their own learning processes; design of the necessary capacities to create open educational resources so as to reduce their production costs, favouring teacher participation in the development of more content.

\section{The CUAED proposal for lifelong learning: Aprendo+ Courses}

The Aprendo+ Courses are a CUAED initiative to bring education to various sectors of the population, promote educational equity, provide a useful educational offer and applicable in everyday life (personal, family, professional), and expand the cultural baggage of the general population. 
The scheme established that Aprendo+ Courses should have the following characteristics:

- $\quad$ Self-managed;

- $\quad$ Aimed at the general public;

- Addressing specific topics;

- Using a close or colloquial language;

- A minimum duration of 6 hours and a maximum one of 20 hours.

The basic structure of the Aprendo + courses considers the level of general components, which includes relevant aspects to the entire course. Within this level, we find the following elements:

- Introduction. It refers to a short text indicating: the content in the course, the organization, the relevance of the content, and what the general objective to achieve is;

- Way of working. This element should include the structure of the course, the materials and available resources, the types of activities, the way to monitor the progress, and the estimated time of studying.

Subsequently, experts develop the units that contain the following elements:

- Introduction - small text to contextualize the unit in the course structure;

- Content - the development of knowledge, skill, or attitude achieved and structured in such a way that the user manages to incorporate and develop it through selfstudying;

- Individual and self-assessing learning activities with clear and complete instructions regarding the product carries out, the characteristics it must have, and how to assess it. Besides, instruments that support self-assessment provided in the form of checklists, rubrics, etc.;

- Self-evaluation, reflected through activities that show the progress of the participants, will be individual and with closed response questions, maintaining congruence with the contents and the learning objective;

- Sources of consultation, listing the bibliographic and hemerographic resources both physical and digital, to which the student can go to learn more about the subject.

\section{Results}

Based on those considerations the Open University and Distance Education Coordination (CUAED) has developed 69 Aprendo+ Courses, like:

- "Feeding: the key to diabetes control", course that recognizes the importance of following a proper diet to prevent and maintain proper control of diabetes mellitus, 
distinguishing the most convenient foods to consume and promote a better quality of life;

- "Learning to say no", course that allows building the necessary skills to say no to everyday situations, without feeling guilty about it;

- "Healthy heart and food", course that recognizes the importance of following a healthy lifestyle to prevent or control cardiovascular diseases and improve your quality of life;

- "Discovering myself in sexuality", course that identifies the aspects that favour selfesteem and allow to express sexuality, the type of erotic-affective relationships that can be built, as well as self-care and protection behaviours for the responsible and satisfactory exercise of sexuality;

- "Economy for everybody: responsible consumption", course that identifies the best process of choice and purchase, both of products and services in present-day Mexico, in order to obtain an improvement in the popular culture of product consumption;

- "When love ends divorce begins", course that identifies the most important basic legal elements of divorce and its processing: the steps to follow from the application to the registration in the marriage certificate; In addition to the institutions where it is requested;

- "The history of art", course that allows you to identify the different eras, styles and names of the creators of the vast world of art history - understood from the art of prehistoric peoples to the offer of contemporary art of our days - in an easy and pleasant way, recognizing the historical, cultural and social context in which they developed;

- "Knowledge plays with no violence", course that recognizes the tools of education for peace and human rights, to address school violence in educational communities;

- "Oral presentations", course that allows you to build oral presentation skills using presentations;

- "Orthography for beginners", course that identifies some of the main spelling rules in Spanish.

The platform launched on social networks in May 2019. At the end of January 2020, it has more than 1,800,000 visits, and more than 460,000 users from more than 110 countries being Mexico, where there is more demand, followed by Latin American countries.

The most demanded course turned out to be "Orthography for beginners" with around 189,000 users. The second one was the "Basic Tools of Microsoft Office 2010, Excel" with approximately 99,000 users, and the third one was "The History of Art" with more than 47,000 users. 


\section{Conclusion}

Lifelong learning is an essential aspect for current and future generations because of the changing environment, and the people need to update themselves to participate in the knowledge society actively.

Universities, as knowledge management institutions, are ideal actors to develop and deliver resources that promote lifelong learning of people with difficulties to access to formal education.

The open educational resources, for their broad characteristics so valued in this knowledge society, are the ideal products that universities can develop, and make available so as to promote lifelong learning of all individuals in society by enabling them with the knowledge, skills and attitudes necessary to function in society.

Considering the information above mentioned, the CUAED has developed the Aprendo+ Courses "to bring education to various sectors of the population, favouring educational equity; providing a useful educational offer, applicable in everyday life like personal, family, labour, professional, and expanding the cultural background of the general population. This initiative added to the social function, which means that the university makes education a common good for all society members.

\section{References}

Alexander, T. (2002). Learning in a global Society. In C. Medel-Añonuevo (Ed.), Integrating Lifelong Learning Perspectives (pp. 77-87). Hamburg, GER: Institute for Education. United Nations Educational, Scientific and Cultural Organization (UNESCO). Retrieved from https://unesdoc.unesco.org/ark:/48223/pf0000126485

Atkins, D. E., Brown, J. S., \& Hammond, A. L. (2007). A Review of the Open Educational Resources (OER) Movement: Achievements, Challenges, and New Opportunities. Report to the William and Flora Hewlett Foundation. Retrieved from http://www.hewlett.org/uploads/files/ReviewoftheOERMovement.pdf

Badat, S. (2013, October). Higher education, transformation and lifelong learning. Paper presented at the ViceChancellor's Mwalimu Julius Nyerere $10^{\text {th }}$ Annual Lecture on Lifelong Learning, University of the Western Cape. Retrieved from http://www.uwc.ac.za/Students/DLL/Documents/Dr\%20Saleem_Badat_DLL_13Octo ber2013.doc

Centre for Educational Research and Innovation (CERI). (2007). Giving Knowledge for Free: The Emergence of Open Educational Resources. Rosewood Drive Danvers, MA: 
Organisation for Economic Co-operation and Development (OCDE). Retrieved from http://www.oecd.org/education/ceri/38654317.pdf

Chee, T. S., Divaharan, S., Tan, L., \& Horn, C. (2011). Self-Directed Learning with ICT: Theory, Practice and Assessment. Singapore: Educational Technology Division. Ministry of Education. Retrieved from https://www.scirp.org/(S(351jmbntvnsjt1aadkposzje))/reference/ReferencesPapers.as px?ReferenceID $=658741$

Kanwar, A., Uvalić-Trumbić, S., \& Butcher, N. (2011). A Basic Guide to Open Educational Resources (OER). Vancouver, BC: United Nations Educational, Scientific and Cultural Organization (UNESCO). Retrieved from https://unesdoc.unesco.org/ark:/48223/pf0000215804

Medel-Añonuevo, C., Ohsako, T., \& Mauch, W. (2001). Revisiting Lifelong Learning for the $21^{\text {st }}$ Century. Hamburg, GER: Institute for Education. United Nations Educational, Scientific and Cultural Organization (UNESCO). Retrieved from https://unesdoc.unesco.org/ark:/48223/pf0000127667

Smidt H., \& Sursock A. (2011). Engaging in Lifelong Learning: Shaping Inclusive and Responsive University Strategies. Brussels, BEL: European University Association. Retrieved from https://eua.eu/resources/publications/404:engaging-in-lifelonglearning-shaping-inclusive-and-responsive-university-strategies.html 